\title{
Evaluating Nurses' Performance Regarding Application of Discharge Plan for Elderly Patients at Beni-Suef University Hospital
}

\author{
Salwa Ahmed Mahommed ${ }^{(1)}$, Hanaa Shapan Husien ${ }^{(2)}$, Amel Abdel Azim \\ Mohamed $^{(2)}$ Eman El- Sherbieny ${ }^{(2)}$ \\ (1) Department of nursing administration, faculty of nursing, Beni-Suef University, Egypt \\ (2) Department of community health nursing, faculty of nursing, Beni-Suef University, Egypt.
}

Email : $\quad$ Tel: +201113987133

\begin{abstract}
Background: Discharge-planning process in hospitals is inherently complex. Information from many sources must be gathered, including patient-specific information regarding functional status and patient and family preferences. Aim of study: the study aimed to evaluate nurses' performance regarding application of discharge plan for elderly patients at Beni-Suef university hospital. Subjects and methods: A descriptive design was used to achieve the aim of the current study. The study was conducted in Beni-Suef university hospital. A convenient Sample of all available nurses (100) in outpatient and in-patient worked at Beni-Suef university hospital and who accepted to participate in the study. Two data collection tools were used to collect data of the current study; tool I: interviewing questionnaire tool, was used to collect nurse knowledge regarding discharge plan and, tool II: observation checklist was used to collect nurses' practice. Results: There is a significant and highly significant relation between studied nurses' performance (knowledge and practice) regarding elderly discharge plan and their age, years of experience and educational qualification. There is a highly positive association between nurses' total level of knowledge and practices regarding the discharge plan. Conclusion and recommendations: The vast majority of nurses had inadequate knowledge and nurses had unsatisfactory practice regarding elderly discharge planning. Providing sufficient educational and instructional program for staff nurses that working with elderly people.
\end{abstract}

Keywords: Application of discharge plan, Elderly patients, Nurses' performance

Receive Date : 5/8/2021

Accept Date: 25/8/2021

Publish Date : 1/1/2022

\section{Introduction}

The Discharge Planning Process (DPP) is a process with five sub processes and a number of steering processes and must be performed when an in-patient needs assistance from primary healthcare and/or community care following discharge. In many industrialized countries, the DPP is theoretically almost identical and relies on similar guidelines and regulations. Discharge planning process in general, the DPP aims to start as soon as practicable after admission and to involve the patient as a partner ${ }^{(1)}$ 
Discharge planning is broadly conceptualized as an interdisciplinary process aiming to prepare for an individual's release from a healthcare service, discharge planning with older adults summarize 'successful' discharge planning as "the development of a comprehensive and effective plan to meet the needs of the patient after discharge with a goal of maintaining or improving health outcomes". Various authors also suggest that in addition to the development of a plan, successful discharge planning entails patient assessment, the provision of information to patients and their involved family members or caregivers, as well as the coordination of follow-up services and evaluation of the discharge plan ${ }^{(2)}$

Ageing is also associated with other life transitions such as retirement, relocation to more appropriate housing, and the death of friends and partners. In developing a public-health response to ageing, it is important not just to consider approaches that ameliorate the losses associated with older age, but also those that may reinforce recovery, adaptation and psychosocial growth ${ }^{(3)}$

Older age is also characterized by the emergence of several complex health states that tend to occur only later in life and that do not fall into discrete disease categories. These are commonly called geriatric syndromes. They are often the consequence of multiple underlying factors and include frailty, urinary incontinence, falls, delirium and pressure ulcers ${ }^{(4)}$.

Common conditions in older age include hearing loss, cataracts and refractive errors, back and neck pain and osteoarthritis, chronic obstructive pulmonary disease, diabetes, depression, and dementia. Furthermore, as people age, they are more likely to experience several conditions at the same time. Geriatric syndromes appear to be better predictors of death than the presence or number of specific diseases. Yet outside of countries that have developed geriatric medicine as a speciality, they are often overlooked in traditionally structured health services and in epidemiological research ${ }^{(5)}$

Factors influencing Healthy Ageing; some of the variations in older people's health are genetic, much is due to people's physical and social environments - including their homes, neighborhoods, and communities, as well as their personal characteristics such as their sex, ethnicity, or socioeconomic status. These factors start to influence the ageing process at an early stage. The environments that people live in as children - or even as developing fetuses combined with their personal characteristics, have long-term effects on how they age ${ }^{(6)}$

Environments also have an important influence on the development and maintenance of healthy behaviors. Maintaining healthy behaviors throughout life, particularly eating a balanced diet, engaging in regular physical activity, and refraining from tobacco use all contribute to reducing the risk of non-communicable diseases and improving physical and mental capacity. Behaviors also remain important in older age (7)

Strength training to maintain muscle mass and good nutrition can both help to preserve cognitive function, delay care dependency, and reverse frailty. Supportive environments enable people to do what is important to them, despite losses in capacity. 
The availability of safe and accessible public buildings and transport, and environments that are easy to walk around are examples of supportive environments ${ }^{(8)}$.

Two thirds of the world's older persons live in the developing regions, where their numbers are growing faster than in the developed regions. In 2050, it is expected that nearly 8 in 10 of the world's older persons will be living in the developing regions. Population ageing the inevitable increases in the share of older persons those results from the decline in fertility and improvement in survival that characterize the demographic transitions occurring throughout the world. Each of the 201 countries or areas with at least 90,000 in- habitants in 2017 is projected to see an increase in the proportion of persons aged 60 or over between 2017 and $2050^{(9)}$

In Egypt, like much another countries worldwide, the elderly population is expanding. Egypt is the most populous country in the Middle East and the second most populous on the African continent (after Nigeria). The population of Egypt represents 1.20 percent of the world's total population which arguably means that one person in every 84 people on the planet is a resident of Egypt ${ }^{(10)}$

The central aim of discharge planning is to prepare for their discharge individuals who are being released from hospital and their families, and to ensure their care needs will be met where they go. A multidisciplinary approach to discharge planning; An element in this process is a multidisciplinary discharge-planning family conference (also called a 'family conference'), which is attended by older adults, family members and healthcare professionals. The family conference is intended to be a collaborative information-sharing forum where everyone is working towards the same goals in creating a plan for discharge and where patients and family members can participate in decision making ${ }^{(11)}$

Homecare nurses and district nurses serve patients who live in a defined geographical area. These nurses provide skilled nursing services, such as assessment and surveillance, wound care, patient education and medical treatments. Homecare nurses and district nurses differ in administrative structure and funding; homecare nurses are usually employed by profit-based hospitals and agencies, and their services are funded by a variety of public and private mechanisms ${ }^{(12)}$

Home care organizer was coined for the professionals who inform people about elderly care and assess what help people may receive, whereas "case managers" execute the assessed help to refer to professionals who are employed by the community and are involved and responsible for DP for home-living patients in need of community care of any type when leaving the hospital ${ }^{(13)}$

Guidance relationship between nurse and client is co-operative by its nature and based in mutual esteem. Guidance is based not only in human autonomy but in client's right for education and health. Autonomy holds in itself another person's human value and respect in self-determination. Nevertheless, respecting these must not result in withdrawal from guidance responsibility even though arising topics are often experienced fairly annoying either by nurse or client. Respecting autonomy in guidance 
adhere to strengthen autonomous decision making and prerequisites for survival. Client decides individually his way of action, holding in sufficient information ${ }^{(14)}$

\section{Significance of the study}

Discharging patients from hospital is a key component of the nurse's role in acute health care settings. It is remarkable that despite government legislation and research, discharge planning remains problematic. The process of discharging patients from acute hospitals is characterized by a range of patient circumstances and needs. Discharge planning for older patients is particularly challenging ${ }^{(11,15)}$, as these patients often have a broad range of needs relating to their health and any care that is needed to support them in their own homes or in community care homes. Previous studies have found discharge processes to be inefficient for such patients. ${ }^{(16,17)}$ Moreover For this group of patients, successful discharge from hospital depends greatly on good planning to provide patient-centred care during their safe journey through the healthcare system to reduce readmissions to hospitals. ${ }^{(18)}$ This process includes effective collaboration and communication between patients, their carers/next of kin and health professionals when moving across care settings. ${ }^{(19)}$ However, in the last decade, a recurrent global theme has emerged where ageing patients are being discharged from hospital 'quicker and sicker'. ${ }^{(20)}$ As the average length of stay decreases, the healthcare provider has less time to coordinate services across settings and to prepare the patients for their situation at home. ${ }^{(21)}$

Nurse is the primary caregiver for the patient and responsible to coordinate the multidisciplinary team to develop discharge plan and provide essential role in educating patients and their caregivers ${ }^{(22)}$. So, the current study aims to evaluate nurses' performance regarding application of discharge plan for elderly patients at Beni-Sueif university hospital.

\section{Aim of the study}

The aim of this study is to evaluate nurses' performance regarding application of discharge plan for elderly patients at Beni-Suef university hospital.

\section{Research questions:}

What is the level of nurses' knowledge and practice regarding application of discharge plan for elderly patients at Beni-Suef university hospital?

\section{Subjects and Methods}

\section{$\underline{\text { Research design: }}$}

Descriptive research design was used in carrying out the current study.

\section{Setting:}

The current study was conducted Beni-Suef university hospital. Beni-Suef university hospital provides multispecialty health services and covers all Beni-Suef citizens 


\section{Subjects:}

A convenient sample of all available nurses (100) in out-patient and in-patient worked at Beni-Suef university hospital and who accepted to participate in the study.

\section{Data collection tools:}

Two data collection tools were used to collect data of the current study;

\section{Tool I: an interviewing questionnaire tool:}

It was developed by researcher after reviewing the national and international related literature. It consists of two parts:

\section{Part I: Socio-demographic characteristics:}

This part aims to collect data about nurses' socio-demographic characteristics and includes: age, gender, educational level, previous courses, years of experience ... etc.

\section{Part II: Nurses' knowledge regarding discharge planning:}

This part aims to collect knowledge of nurses regarding discharge planning.it is consists of 8 multiple choice question, Each question had different number of correct answers, and the nurses were asked to choose more than one answer, for each answer, the correct answer scored as (1) and (0) for incorrect answer.

\section{Scoring system:}

Adequate knowledge ---- $\geq 60 \%$ of total knowledge score. Inadequate knowledge ------- $<60 \%$ of total knowledge score.

\section{Tool II: Nurses' practice regarding discharge plan assessment check list:}

This part aims to collect studied nurses' practice discharge plan, it consists of items related nurses practice discharge assessment tasks, nurses practice at 5-7 days prior discharge ,1-2 days prior discharge and at the day of discharge. Practice scores were "completely done", "partially done "and "not done" which scored 2 for completely done, 1 for partially done one and zero for not done.

\section{Scoring system:}

High satisfactory practice :---------> 75\% of total practice score.

Satisfactory practice: $-60-75 \%$ of total practice score.

Unsatisfactory practice :----------<60\% of total practice score .

\section{Tools validity:}

Validity of the study tools was assessed by jury group consisted of three experts in nursing from faculties of nursing. Jury group members judge tools for comprehensiveness, 
accuracy and clarity in language. Based on their recommendations correction, addition and / or omission of some items were done

\section{Tools Reliability:}

The study tool was tested for its internal consistency using Cronbach's Alpha. It was 0.863 for the study tool.

\section{Pilot study:}

Pilot study was carried out on $10 \%$ of the total study sample (10 nurses) to evaluate the applicability, efficiency, clarity of tools, assessment of feasibility of field work, beside to detect any possible obstacles that might face the investigator and interfere with data collection. Necessary modifications were done based on the pilot study findings such as (omission of some questions from tool) in order to strengthen their contents or for more simplicity and clarity. The pilot sample was excluded from the main study sample

\section{Field work:}

Data collections of the study take four months. Data collection of the study was started at the beginning of September 2020, and completed by the end of December 2020. The investigator attended at Beni-Suef university hospital. Three days per week from 9 am to $2 \mathrm{pm}$ for nurses.

The investigator first explained the aim of the study to the nurses and reassures them that information collected was treated confidentiality and that it was used only for the purpose of the research. The investigator meted nurses at Beni-Suef university hospital, and the investigator observe red nurses' performance during their work, the investigator evaluates each nurse and each nurses take from 15: 20 minutes for observation checklist.

\section{Administrative Design:}

An official letter requesting permission to conduct the study was directed from the dean of the faculty of nursing Beni-Suef University to Beni-Suef university hospital to obtain their approval to carry out this study. This letter included the aim the study and photocopy from data collection tools in order to get their permission and help for collection of data.

\section{Ethical Considerations:}

Prior study conduction, ethical approval was obtained from the scientific research ethical committee of the faculty of nursing, Beni- Suef University. The researcher met director of previous mentioned settings to clarify the aim of the study and take their approval. The researcher also met the staff nurses to explain the purpose of the study and obtain their approval to participate in the study. They were reassured about the anonymity and confidentiality of the collected data, which was used only for the purpose of scientific research. The subjects' right to withdraw from the study at any time was assured. 


\section{Statistical analysis:}

Data entry and statistical analysis were done using (SPSS) statistical software package. Quality control was at the stage of coding and data entry. Data were presented using descriptive statistics in the form of frequencies and percentage for qualitative variables; mean and standard deviation for quantitative variable. Qualitative categorical variables were compared Chi-square (X2) test; the hypothesis that the row and column variables are independent, without indicating strength or direction of the relationship, Analysis of variance (ANOVA) test. Statistical significance was considered at (P-value $<0.05)$.

\section{Results:}

Table 1: shows that more than two thirds (68\%) of nurses' ages ranged from 20:30 years old. Nearly three quarters $(70 \%)$ of nurses were female. Majority $(89 \%)$ of them had technical nursing institute, and $(92 \%)$ of them were worked staff nurse. More than three fifths $(61 \%)$ of nurses had experience less than 5 years.

Table (1) Percentage distribution of demographic characteristics of the studied nurses $(n=100)$.

\begin{tabular}{|l|c|c|}
\hline \multicolumn{1}{|c|}{ Demographic characteristics } & No. & \% \\
\hline 1. Age & 7 & 7 \\
\hline - <20 years & 68 & 68 \\
\hline - 20:30 years & 22 & 22 \\
\hline - 30:50 years & 3 & 3 \\
\hline - >50 years & & \\
\hline 2. Gender & 30 & 30 \\
\hline - Male & 70 & 70 \\
\hline - Female & & \\
\hline 3. Qualification & 5 & 5 \\
\hline - Diploma in Nursing & 89 & 89 \\
\hline - Technical Nursing Institute & 2 & 2 \\
\hline - Bachelor Degree & 4 & 4 \\
\hline - Post Graduate Nurse & & \\
\hline 4. Nursing Position & 92 & 92 \\
\hline - Staff nurse & 8 & 8 \\
\hline - Head nurse/ Nursing supervisor & 0 & 0 \\
\hline - Nursing director & & \\
\hline 5. Past Experience & 61 & 61 \\
\hline - <5 years & 23 & 23 \\
\hline - 5:10 years & 16 & 16 \\
\hline - >10 years & & \\
\hline
\end{tabular}


Figure (1): reveals that, more than three quarters $(77 \%)$ of the studied nurses had inadequate knowledge about total elderly discharge plan. While, less than one quarter $(23 \%)$ of the studied nurses had adequate knowledge about total elderly discharge plan.

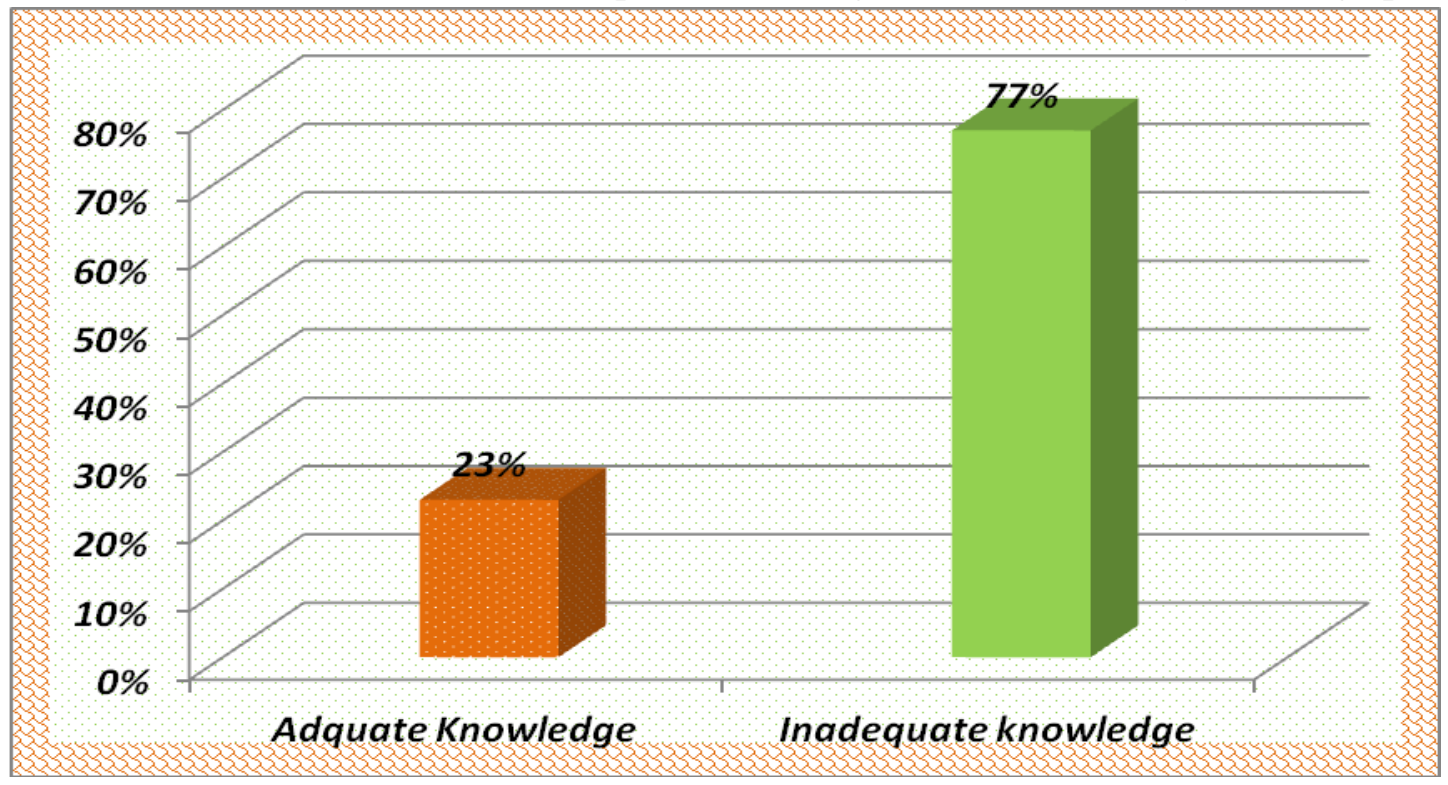

Figure (1): percentage distribution of studied nurses' knowledge score regarding discharge plan.

Figure (2): reveals, nearly half (44\%) of the studied nurses had unsatisfactory practice regarding the elderly discharge plan. While, minority $(17 \%)$ of the studied nurses had highly satisfactory practice regarding the elderly discharge plan.

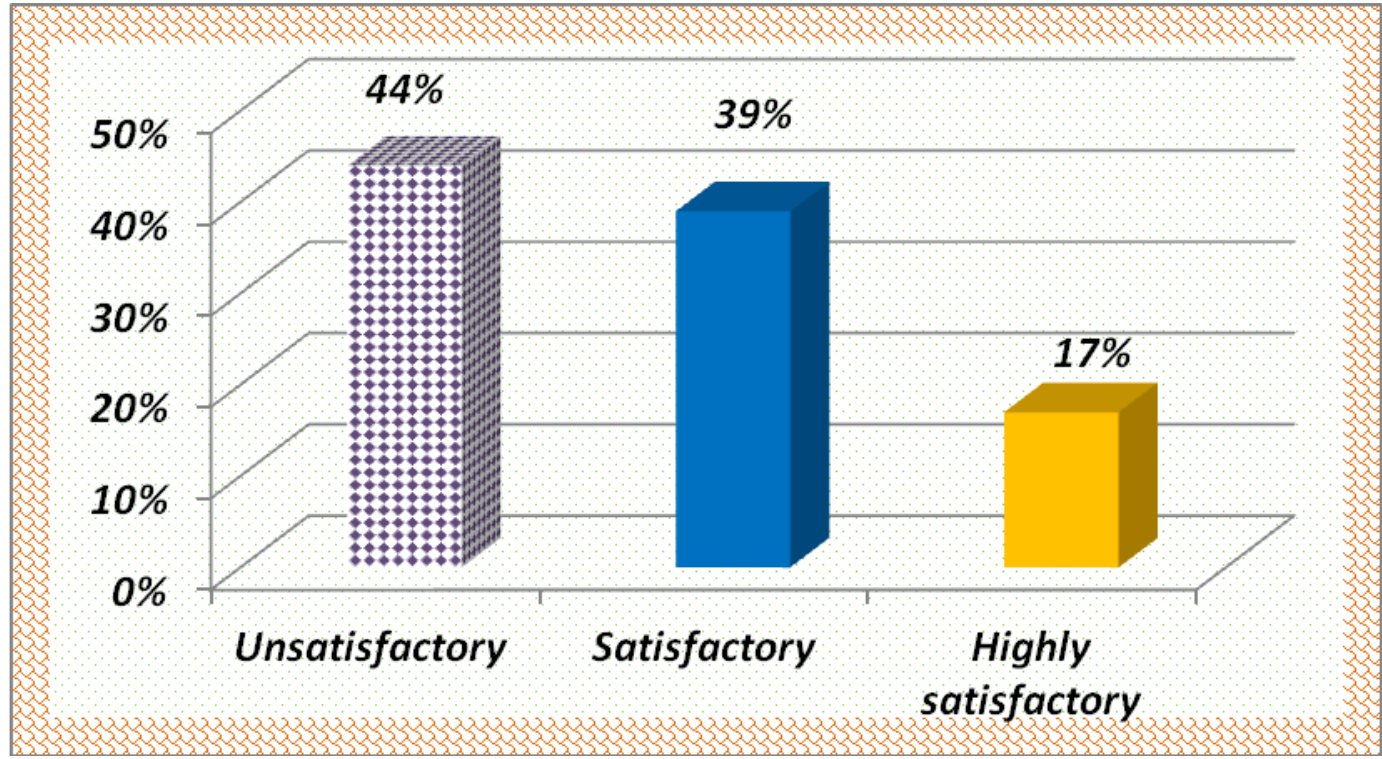

Figure (2): percentage distribution of studied nurses' practice level regarding discharge plan. 
Table 2: shows that there is a highly statistically significant relation between studied nurses' total level of knowledge regarding discharge plan and their ages, qualifications and past experience. Also, there is a statistically significant relation between nurses' total level of knowledge and their nursing position. While, there is no statistically significant relation between studied nurses' total level of knowledge and their gender.

Table (2): The relation between nurses' demographic characteristics and their total level of knowledge $(n=100)$

\begin{tabular}{|c|c|c|c|c|c|c|}
\hline \multirow[t]{2}{*}{ Demographic characteristics } & \multicolumn{2}{|c|}{$\begin{array}{l}\text { Inadequate } \\
\text { knowledge }\end{array}$} & \multicolumn{2}{|c|}{$\begin{array}{c}\text { Adequate } \\
\text { knowledge }\end{array}$} & \multirow[t]{2}{*}{$\overline{\mathrm{X}^{2}}$} & \multirow[t]{2}{*}{$\overline{\text { P-Value }}$} \\
\hline & No & $\%$ & No & $\%$ & & \\
\hline \multicolumn{5}{|l|}{ 1. Age } & \multirow[t]{5}{*}{89.73} & \multirow[t]{5}{*}{$<0.001 * *$} \\
\hline$-<20$ years & 7 & 0 & $9.1 \%$ & $0.0 \%$ & & \\
\hline$-20: 30$ years & 68 & 0 & $88.3 \%$ & $0.0 \%$ & & \\
\hline$-30: 50$ years & 2 & 20 & $2.6 \%$ & $87.0 \%$ & & \\
\hline$->50$ years & 0 & 3 & $0.0 \%$ & $13.0 \%$ & & \\
\hline \multicolumn{5}{|l|}{ 2. Gender } & \multirow[t]{3}{*}{0.971} & \multirow[t]{3}{*}{$>0.05$} \\
\hline -Male & 25 & 5 & $32.5 \%$ & $21.7 \%$ & & \\
\hline -Female & 52 & 18 & $67.5 \%$ & $78.3 \%$ & & \\
\hline \multicolumn{5}{|l|}{ 3. Qualification } & \multirow[t]{5}{*}{22.34} & \multirow[t]{5}{*}{$<0.001 * *$} \\
\hline -Diploma in Nursing & 5 & 0 & $6.5 \%$ & $0.0 \%$ & & \\
\hline -Technical Nursing Institute & 72 & 17 & $93.5 \%$ & $73.9 \%$ & & \\
\hline -Bachelor Degree & 0 & 2 & $0.0 \%$ & $8.7 \%$ & & \\
\hline -Post Graduate Nurse & 0 & 4 & $0.0 \%$ & $17.4 \%$ & & \\
\hline \multicolumn{5}{|l|}{ 4. Nursing Position } & \multirow[t]{3}{*}{7.66} & \multirow[t]{3}{*}{$<0.05^{*}$} \\
\hline -Staff nurse & 74 & 18 & $96.1 \%$ & $78.3 \%$ & & \\
\hline $\begin{array}{l}\text {-Head nurse/ Nursing } \\
\text { supervisor }\end{array}$ & 3 & 5 & $3.9 \%$ & $21.7 \%$ & & \\
\hline \multicolumn{5}{|l|}{ 5. Years of Experience } & \multirow[t]{4}{*}{51.70} & \multirow[t]{4}{*}{$<.0001 * *$} \\
\hline$<5$ years & 59 & 2 & $76.6 \%$ & $8.7 \%$ & & \\
\hline$-5: 10$ years & 16 & 7 & $20.8 \%$ & $30.4 \%$ & & \\
\hline ->10 years & 2 & 14 & $2.6 \%$ & $60.9 \%$ & & \\
\hline
\end{tabular}

(**) Highly statistically significant correlation at $\mathrm{P}$-value $<0.01$

(*) Statistically significant correlation at $\mathrm{P}$-value $<0.05$

Table 3: shows that there is a statistically significant relation between studied nurses' total level of practice and their qualification and past experience. While there is no statistically significant relation between studied nurses' total level of practice and their nursing position. 
Table (3): The relation between nurses' demographic characteristics and their total level of practice $(n=100)$

\begin{tabular}{|c|c|c|c|c|c|c|c|c|}
\hline \multirow[t]{2}{*}{$\begin{array}{l}\text { Demographic } \\
\text { characteristics }\end{array}$} & \multicolumn{2}{|c|}{$\begin{array}{c}\text { Unsatisfactory } \\
\text { practice }\end{array}$} & \multicolumn{2}{|c|}{$\begin{array}{c}\text { Satisfactory } \\
\text { practice }\end{array}$} & \multicolumn{2}{|c|}{$\begin{array}{c}\text { Highly } \\
\text { Satisfactory } \\
\text { practice }\end{array}$} & \multirow[t]{2}{*}{$\mathbf{X}^{2}$} & \multirow[t]{2}{*}{ P-Value } \\
\hline & No & $\%$ & & & No & $\%$ & & \\
\hline \multicolumn{7}{|l|}{ 1. Age } & \multirow[t]{5}{*}{75.92} & \multirow[t]{5}{*}{$<0.001 * *$} \\
\hline$-<20$ years & 7 & 0 & 0 & $15.9 \%$ & $0.0 \%$ & $0.0 \%$ & & \\
\hline$-20: 30$ years & 37 & 31 & 0 & $84.1 \%$ & $79.5 \%$ & $0.0 \%$ & & \\
\hline$-30: 50$ years & 0 & 6 & 16 & $0.0 \%$ & $15.4 \%$ & $94.1 \%$ & & \\
\hline$->50$ years & 0 & 2 & 1 & $0.0 \%$ & $5.1 \%$ & $5.9 \%$ & & \\
\hline \multicolumn{7}{|l|}{ 2. Gender } & \multirow[t]{3}{*}{31.78} & \multirow[t]{3}{*}{$<0.001 * *$} \\
\hline -Male & 25 & 0 & 5 & $56.8 \%$ & $0.0 \%$ & $29.4 \%$ & & \\
\hline -Female & 19 & 39 & 12 & $43.2 \%$ & $100.0 \%$ & $70.6 \%$ & & \\
\hline \multicolumn{7}{|l|}{ 3. Qualification } & \multirow[t]{5}{*}{15.74} & \multirow[t]{5}{*}{$<0.05^{*}$} \\
\hline -Diploma in Nursing & 3 & 2 & 0 & $6.8 \%$ & $5.1 \%$ & $0.0 \%$ & & \\
\hline -Technical Nursing Institute & 41 & 35 & 13 & $93.2 \%$ & $89.7 \%$ & $76.5 \%$ & & \\
\hline -Bachelor Degree & 0 & 0 & 2 & $0.0 \%$ & $0.0 \%$ & $11.8 \%$ & & \\
\hline -Post Graduate Nurse & 0 & 2 & 2 & $0.0 \%$ & $5.1 \%$ & $11.8 \%$ & & \\
\hline \multicolumn{7}{|l|}{ 4. Nursing Position } & \multirow[t]{3}{*}{2.6} & \multirow[t]{3}{*}{$>0.05$} \\
\hline -Staff nurse & 41 & 37 & 14 & $93.2 \%$ & $94.9 \%$ & $82.4 \%$ & & \\
\hline $\begin{array}{l}\text {-Head nurse/ Nursing } \\
\text { supervisor }\end{array}$ & 3 & 2 & 3 & $6.8 \%$ & $5.1 \%$ & $17.6 \%$ & & \\
\hline \multicolumn{7}{|l|}{ 5. Years of Experience } & \multirow[t]{4}{*}{7.10} & \multirow[t]{4}{*}{$<0.05^{*}$} \\
\hline$<5$ years & 38 & 21 & 2 & $86.4 \%$ & $53.8 \%$ & $11.8 \%$ & & \\
\hline$-5: 10$ years & 5 & 15 & 3 & $11.4 \%$ & $38.5 \%$ & $17.6 \%$ & & \\
\hline$->10$ years & 1 & 3 & 12 & $2.3 \%$ & $7.7 \%$ & $70.6 \%$ & & \\
\hline
\end{tabular}

(**) Highly statistically significant correlation at $\mathrm{P}$-value $<0.01$

(*) Statistically significant correlation at $\mathrm{P}$-value $<0.05$

Table 4: reveals that there is highly positive association between studied nurses' total level of knowledge and their total level of practices regarding the discharge plan.

Table (4): Correlation between nurses' total level of knowledge and their total level of practices $(n=100)$

\begin{tabular}{||l|l|c|}
\hline \multicolumn{2}{|l|}{} & \multicolumn{2}{c|}{$\begin{array}{c}\text { Total level of discharge plan } \\
\text { knowledge }\end{array}$} \\
\hline $\begin{array}{l}\text { Total level of practices regarding discharge } \\
\text { plan }\end{array}$ & $\mathrm{r}$ & $0.537 * *$ \\
\cline { 2 - 4 } & $\mathrm{P}$ & $<0.001 * *$ \\
\hline
\end{tabular}

(*) Statistically significant correlation at $\mathrm{P}$-value $<0.05$ 


\section{Discussion:}

Old age may be defined as the stage from age 65 until death. During this stage, most people retire from work and no longer have the major responsibility of caring for others. Physically, older adults tend to have a decline in stamina, strength, reflex time, and the senses. Other physical changes that occur in old age include a decrease in the following: Heart output, Kidney function, Lung capacity, Number of brain cells. Because the immune system also becomes less efficient with age, older adults are increasingly susceptible to serious illnesses such as cancer, cardiovascular disease, and pneumonia. Osteoporosis, or loss of bone density, is also common in older adults, particularly in females. Mental deterioration may occur as well, especially in people with Alzheimer's disease and certain other diseases ${ }^{(23)}$.

Discharge planning is broadly conceptualized as an interdisciplinary process aiming to prepare for an individual's release from a healthcare service, discharge planning with older adults summarize 'successful' discharge planning as "the development of a comprehensive and effective plan to meet the needs of the patient after discharge with a goal of maintaining or improving health outcomes". Various authors also suggest that in addition to the development of a plan, successful discharge planning entails patient assessment, the provision of information to patients and their involved family members or caregivers, as well as the coordination of follow-up services and evaluation of the discharge plan ${ }^{(4)}$.

So, the current study aimed to evaluate nurses' performance regarding application of discharge plan for elderly patients at Beni-Suef university hospital

Regarding nurses' ages, the current study showed that more than two thirds of nurses' ages ranged from 20:30 years old. This result is in agreement with Mahdy, et al., (2019) ${ }^{(24)}$ that conducted a study entitled "Efficacy of Safety Measures and Discharge Planning Guidelines on Nurses for Enteral Nutrition of Comatose Patients" and found that majority of nurses had ages from 20: 30 years. Conversely, this result is in disagreement with Nielsen, et al., (2018) ${ }^{(25)}$ that conducted a study entitled "Effectiveness of the "elderly activity performance intervention" on elderly patients' discharge from a short-stay unit at the emergency department" and found that majority of nurses had ages more than 30 years.

Regarding nurses' gender, the current study showed that nearly three quarters of nurses were female. This result is supported with Jarelnape, (2021) ${ }^{(26)}$ that conducted a study entitled " Nurses' knowledge about the discharge plan for patients after cardiac surgery at the Sudan Heart Institute" and found that majority of nurses were female. On the other hand, this result is in disagreement with Facchinetti, et al., (2019) ${ }^{(27)}$ that conducted a study entitled " Discharge of older patients with chronic diseases: What nurses do and what they record" and found that more than half of nurses were female.

Regarding nurses' qualification, the current study showed that majority of them had technical nursing institute. This result is accordance with Kageyama, \& Asano, $\mathbf{( 2 0 1 7 )}^{(28)}$ that conducted a study entitled " Thinking about the patient's wishes: practical 
wisdom of discharge planning nurses in assisting surrogate decision-making" and found that that majority of nurses had technical nursing institute. In contrast, this result is in disagreement with Mahdy, et al., (2019) ${ }^{(24)}$ that conducted a study entitled "Efficacy of Safety Measures and Discharge Planning Guidelines on Nurses for Enteral Nutrition of Comatose Patients" and found that more than one third of nurses had bachelor degree in nursing.

Regarding nurses' experience, the current study showed that more than half of nurses had experience less than 5 years. This result is congruence with Mol, et al., (2017) ${ }^{(29)}$ that conducted a study entitled " Using an intervention mapping approach to develop a discharge protocol for intensive care patients" and found that more than half of nurses had experience less than 5 years. Conversely, this result is in disagreement with Nielsen, et al., (2018) ${ }^{(25)}$ that conducted a study entitled " Effectiveness of the "elderly activity performance intervention" on elderly patients' discharge from a shortstay unit at the emergency department" and found that majority of nurses had experience ranged from 5: 10 years

Regarding nurses' knowledge about the discharge plan, the current study revealed that the vast majority of the studied nurses had inadequate knowledge regarding elderly people discharge plan, these findings are agreed with Lalani and Gulzar , (2017), ${ }^{(30)}$ in the study to "assess nurses' knowledge, perceptions, and actual practice towards DP for patient", it was revealed that a large percentage of nurses had a lack of knowledge regarding DP which affects their practice in DP process. Also these findings were supported by this may be due to the lack of training program regarding discharge plan at the study setting. In addition Mohammad, et al., (2016), ${ }^{(31)}$ in the study to investigate nurses' knowledge towards DP ,Study shows level of nurses' knowledge towards DP were deficit in different domain, mainly in Nurses' knowledge towards patients follow-up. Moreover this result is supported with Maribo, et al., (2019) ${ }^{(32)}$ that conducted a study entitled " Returning to everyday life after discharge from a short-stay unit at the Emergency Department - a qualitative study of elderly patients' experiences" and found that majority of nurses had low level of knowledge and perception of discharge planning. On the other hand, this result is in disagreement with Zakiyah, \& Basuki, (2017) ${ }^{(33)}$ that conducted a study entitled "Relationship between nurse characteristics with discharge planning implementation" and found that more than half of nurses had a high knowledge and perception about discharge planning implementation for their patients. Also this result is in disagreement with Biese,et al., (2018) $)^{(34)}$ that conducted a study entitled " Telephone follow-up for older adults discharged to home from the emergency department" and found that more than one third of nurses had inadequate knowledge regarding discharge planning.

Regarding nurses' total level of practices about discharge planning process, the current study revealed that majority of nurses had unsatisfactory practice about total level of practices regarding discharge plan. While, minority of nurses had satisfactory practice about total level of practice regarding discharge plan. From the researcher point 
of view, this result may be due to nurses hadn't knowledge about discharge planning that effect negatively on their performance.

This result is accordance with Nicosia, et al., (2018) ${ }^{(35)}$ that conducted a study entitled "Nurses' perspectives on lean redesigns to patient flow and inpatient discharge process efficiency" and found that majority of nurses had unsatisfactory practice about discharge planning. Also, this result is in agreement with Tahery, et al., (2019) ${ }^{(36)}$ that conducted a study entitled "Nursing teaching role performance from the viewpoint of discharging patient from the Abadan and Khorramshahr hospitals" and found that highest percentage of nurses had unsatisfactory practice about discharge planning.

Regarding relation between studied nurses' educational qualification and their total knowledge and total level of practice, the current study showed that there is a highly significant relation. This result is accordance with (Zakiyah \& Basuki, 2017) ${ }^{(33)}$, in the study to "explore Relationship between nurse characteristics with discharge planning implementation", it revealed a strong relationship between the level of education and the implementation of DP (p-value .023). A higher level of education made nurses more systematic and logical in planning for discharge. In constract, this result is in disagreement with Mahdy, et al., (2019) ${ }^{(24)}$ that conducted a study entitled "Efficacy of Safety Measures and Discharge Planning Guidelines on Nurses for Enteral Nutrition of Comatose Patients" and found that more than one third of nurses had bachelor degree in nursing.

As regarding the relation between studied nurses' years of experience and their total knowledge and total level of practice, the current study showed that there was a highly significant and significant relation respectively. This result is accordance with (Atwal, 2012) $)^{(37)}$, in the study to "evaluate nurses' perceptions of discharge planning in acute health care: A case study in one British teaching hospital", it was reported that the number of years of nursing experience affected patients' recovery and health outcomes positively). Moreover Mol, et al., (2017) ${ }^{(29)}$ conducted a study entitled " Using an intervention mapping approach to develop a discharge protocol for intensive care patients" and found that there was a significant relation between nurses years of experience and nurses knowledge and practice .In contrast, another study conducted in Iraq reported that new graduates and young nurses were more excited and interested in performing DP; this study was the only one to discover a relationship between age and DP (Mohammad, et al, 2016) ${ }^{(31)}$.Also Nielsen, et al., (2018) ${ }^{(25)}$ that conducted a study entitled " Effectiveness of the "elderly activity performance intervention" on elderly patients' discharge from a short-stay unit at the emergency department" and found that there was no significant relation between nurses performance and years of experience.

Regarding correlation between nurses' total level of knowledge and their total level of practices, the current study revealed that there is a highly positive association positive correlation between studied nurses' total level of knowledge and their total level of practices. These findings are agreed with Lalani and Gulzar , 2017) ${ }^{(30)}$, who reported that nurses knowledge regarding DP is highly affect their practice in DP process. In addition Jannah, et al., (2019) ${ }^{(38)}$, who that conducted a study entitled 
"Discharge planning model with approach of method in improving patients' readiness for discharge in hospitals" and found that there is association correlation between nurses' total level of knowledge and their total practices. On the other hand, this result is in disagreement with Christiansen, et al., (2017) ${ }^{(39)}$, that conducted a study entitled "Nurses' use and perception of an information and communication technology system for improving coordination during hospital discharges" and found that there is negative correlation between nurses' total level of knowledge and perception and their total practices.

\section{Conclusion}

The current study concluded that more than three quarters of nurses had inadequate knowledge about total elderly discharge plan .In addition nearly half of them had unsatisfactory practice toward discharge plan.

Furthermore there is a highly positive association between nurses' total level of knowledge and their total level of practices regarding elderly discharge plan.

Also there is a significant and highly significant relation between studied nurses' performance regarding elderly discharge plan and their age, years of experience and educational qualification

\section{Recommendation:}

In the light of results of this study, the following recommendations were suggested:

- Enhancing nurses knowledge and practice regarding the elderly discharge plan should be improved through an instructional and educational Programs

- Enhance DP communication, writing goals skills between staff nurses and elderly patients and their families.

- Provide requirements and needs of elderly patients to provide plan of care after discharge.

- Further studies should be conducted in different settings.

\section{References}

1. Piniella, N., Fuller, T. E., Pong, D., Pardo, M., Bessa, N., ... \& Schnipper, J. L. (2021). Evaluation of electronic health record-integrated digital health tools to engage hospitalized patients in discharge preparation. Journal of the American Medical Informatics Association, 28(4), 704-712.

2. Denson, L., Winefield, H., \& Beilby, J. (2018). Discharge planning for long-term care needs: the values and priorities of older people, their younger relatives and health professionals. Scandinavian Journal of Caring Sciences, 27, 3-12. doi: 10.1111/j.14716712.2012.00987.x

3. AlAhmari, M. (2020). Readmission Elderly Critically Patients. In Ventilatory Support and Oxygen Therapy in Elder, Palliative and End-of-Life Care Patients (pp. 279-285). Springer, Cham.

4. Blomström-Lundqvist, C., Traykov, V., Erba, P. A., Burri, H., Nielsen, J. C., Bongiorni, M. G., ... \& Strathmore, N. (2020). European Heart Rhythm Association 
(EHRA) international consensus document on how to prevent, diagnose, and treat cardiac implantable electronic device infections - endorsed by the Heart Rhythm Society (HRS), the Asia Pacific Heart Rhythm Society (APHRS), the Latin American Heart Rhythm Society (LAHRS), International Society for Cardiovascular Infectious Diseases (ISCVID) and the European Society of Clinical Microbiology and Infectious Diseases (ESCMID) in collaboration with the European Association for .... EP Europace, 22(4), 515-549.

5. Estes, C., Biggs, S. \& Phillipson, C. (2018). Social Theory, Social Policy and Ageing. Berkshire, UK: Open University Press

6. Fernandes, B. D., Almeida, P. H. R. F., Foppa, A. A., Sousa, C. T., Ayres, L. R., \& Chemello, C. (2020). Pharmacist-Led medication reconciliation at patient discharge: a scoping review. Research in Social and Administrative Pharmacy, 16(5), 605-613.

7. Frumkin, K. (2020). Toppling oranges: death, disability, decline, and readmission of community-dwelling elderly patients after an emergency department visit. The Journal of emergency medicine, 58(2), 339-345.

8. Grimmer, M., Riener, R., Walsh, C. J., Seyfarth, A. (2019): Mobility related physical and functional losses due to aging and disease-a motivation for lower limb exoskeletons: Journal of neuroengineering and rehabilitation, 16(1), 2.

9. Mizuma, K., Amitani, M., Mizuma, M., Kawazu, S., Sloan, R. A., Ibusuki, R., ... \& Owaki, T. (2020). Clarifying differences in viewpoints between multiple healthcare professionals during discharge planning assessments when discharging patients from a longterm care hospital to home. Evaluation and Program Planning, 82, 101848.

10. Harvey, L. (2019). Social research glossary. Quality Research International. Retrieved from: http://www.qualityresearchinternational.com/socialresearch/csr.htm

11. Bauer, M., Fitzgerald, L., Haesler, E., \& Manfrin, M. (2019). Hospital discharge planning for frail older people and their family. Are we delivering beat practice? A review of the evidence. Journal of Clinical Nursing, 18, 2539-2546. doi: 10.1111/j.13652702.2008.02685.x

12. Auerbach, C., Mason, S., \& Heft Laporte, H. (2017). From hospital to nursing facility: Factors influencing decisions. Health and Social Work, 34(1) 8-15.

13. Kobewka, D. M., Mulpuru, S., Chassé, M., Thavorn, K., Lavallée, L. T., English, S. W., ... \& McIsaac, D. I. (2020). Predicting the need for supportive services after discharged from hospital: a systematic review. BMC health services research, 20(1), 1-10.

14. Kane, R. (2017). Guidance relationship between nurse and client; Finding the right level of post hospital care "We didn't realize there was any other option for him". Journal of American Medical Association, 305(3), 284-293.

15. Mitchell F., Gilmour M., \& Mclaren G. (2010). Hospital discharge: A descriptive study of the patient journey for frail older people with complex needs. Journal of Integrated Care, 18, 30-36. [Google Scholar]

16. Connelly M., Grimshaw J., Dodd M., Cawthorne J., Hulme T., Everitt S., ... Deaton C. (2015). Systems and people under pressure: The discharge process in an acute hospital. Journal of Clinical Nursing, 18, 549-558. [PubMed] [Google Scholar

17. National Audit Office (2016) Discharging older patients from hospital.

18. Watts R, Gardner H, Pierson J. (2015); Factors that enhance or impede critical care nurses' discharge planning practices. Intensive Crit Care Nurs;21:302-13.

19. Storm M, Siemsen IMD, Laugaland K, et al. (2014); Quality in transitional care of the elderly: key challenges and relevant improvement measures. Int J Integr Care ;14:e013.

20. Galvin EC, Wills T, Coffey A.(2017); Readiness for hospital discharge: a concept analysis. J Adv Nurs ;73:2547-57.

21. Suwan N, Panuthai S, Lasuka D, et al.(2018); Factors influencing readiness for hospital discharge among Thai older persons with chronic obstructive pulmonary disease. Pacific Rim International Journal of Nursing Research ;22:156-68. 
22. Arnon Z, Steinberger D, Attias S, Grimberg O, Peterfreund I, Schiff E, \& Keshet Y. (2018): Nurses as boundary actors: Promoting integrative medicine in hospital wards. Complementary therapies in clinical practice, 31, 96-103.

23. Morris, J., Winfield, L., \& Young, K. (2018). Registered nurses' perceptions of the discharge planning process for adult patients in an acute hospital. Journal of Nursing Education and Practice, 2(1), 28-38. https://doi.org/10.5430/jnep.v2n1p28

24. Mahdy, A. Y., Hamed, L. A., \& Shehata, A. A. M. (2019). Efficacy of Safety Measures and Discharge Planning Guidelines on Nurses for Enteral Nutrition of Comatose Patients. International Journal of Novel Research in Healthcare and Nursing, 6(3), 220231.

25. Nielsen, L. M., Maribo, T., Kirkegaard, H., Petersen, K. S., Lisby, M., \& Oestergaard, L. G. (2018). Effectiveness of the "elderly activity performance intervention" on elderly patients' discharge from a short-stay unit at the emergency department: a quasiexperimental trial. Clinical Interventions in Aging, 13, 737.

26. Jarelnape, A. A. A. (2021). Nurses' knowledge about the discharge plan for patients after cardiac surgery at the Sudan Heart Institute. Majmaah Journal of Health Sciences, 9(2), 7179.

27. Facchinetti, G., Ianni, A., Piredda, M., Marchetti, A., D’Angelo, D., Dhurata, I., ... \& De Marinis, M. G. (2019). Discharge of older patients with chronic diseases: What nurses do and what they record. An observational study. Journal of clinical nursing, 28(9-10), 1719-1727.

28. Kageyama, Y., \& Asano, M. (2017). Thinking about the patient's wishes: practical wisdom of discharge planning nurses in assisting surrogate decision-making. Scandinavian Journal of caring sciences, 31(4), 796-804.

29. Mol, M., Nijkamp, M., Markham, C., \& Ista, E. (2017). Using an intervention mapping approach to develop a discharge protocol for intensive care patients. BMC health services research, 17(1), 1-13.

30. Lalani, N. S., \& Gulzar, A. Z. (2017). Nurses' role in patients'discharge planning at the Aga Khan University Hospital, Pakistan. Journal for Nurses in Professional Development, 17(6), 314-319 .

31. Mohammad, M., Fadil, A., \& Ahmed, S. A. (2016). Assessment of nurses' knowledge concerning discharge planning for patients 'with open heart surgery in Cardiac Centre at Baghdad. City, 6(10), 162-167.

32. Maribo, T., Nielsen, L. M., Gregersen Østergaard, L., Kirkegaard, H., \& Petersen, K. S. (2019). Returning to everyday life after discharge from a short-stay unit at the Emergency Department - a qualitative study of elderly patients' experiences. International journal of qualitative studies on health and well-being, 14(1), 1563428.

33. Zakiyah, A., \& Basuki, D. (2017). Relationship between nurse characteristics with discharge planning implementation. International Journal of Nursing and Midwifery Science (Ijnms), 1(2), 193-197.

34. Biese, K. J., Busby-Whitehead, J., Cai, J., Stearns, S. C., Roberts, E., Mihas, P., ... \& Kizer, J. S. (2018). Telephone follow-up for older adults discharged to home from the emergency department: A pragmatic randomized controlled trial. Journal of the American Geriatrics Society, 66(3), 452-458.

35. Nicosia, F. M., Park, L. G., Gray, C. P., Yakir, M. J., \& Hung, D. Y. (2018). Nurses' perspectives on lean redesigns to patient flow and inpatient discharge process efficiency. Global qualitative nursing research, 5, 2333393618810658.

36. Tahery, N., Razieh, S., Hamidreza, A., Geravandi, S., \& Mohammadi, M. J. (2019). Nursing teaching role performance from the viewpoint of discharging patient from the Abadan and Khorramshahr hospitals. Clinical Epidemiology and Global Health, 7(4), 611614. 
37. Atwal, A. (2012). Nurses' perceptions of discharge planning in acute health care: A case study in one British teaching hospital. Journal of Advanced Nursing, 39(5), 450-458. https://doi. org/10.1046/j.1365-2648.2012.02310.x

38. .Jannah, N., Sukartini, T., \& Hidayat, A. A. A. (2019). Discharge planning model with approach of method in improving patients' readiness for discharge in hospitals. Indian Journal of Public Health Research and Development, 10(1), 288-292.

39. Christiansen, L., Fagerström, C., \& Nilsson, L. (2017). Nurses' use and perception of an information and communication technology system for improving coordination during hospital discharges: a survey in swedish primary healthcare. CIN: Computers, Informatics, Nursing, 35(7), 358-363. 